\title{
ASSESSING CEAB GRADUATE ATTRIBUTES AT RYERSON UNIVERSITY: FRAMEWORK AND INGREDIENTS FOR SUCCESS
}

\author{
*Easa, S M; **Lachemi, M \\ Faculty of Engineering, Architecture and Science, Ryerson University, Ontario, Canada \\ seasa@ryerson.ca
}

\section{INTRODUCTION}

The Canadian Engineering Accreditation Board (CEAB) has recently introduced a new criterion for accreditation of engineering programs. The criterion included 12 graduate attributes. Each engineering program must have a system in place for assessing these attributes and using the assessment results to continuously improve the engineering program. The development of a system for assessing CEAB graduate attributes at Ryerson University has started in April 2010. This paper highlights the developed system, including framework, elements, process, and ingredients for success.

\section{METHODS}

The Faculty of Engineering, Architecture and Science (FEAS) at Ryerson University has eight engineering programs and seven science programs. The development of the CEAB assessment system was driven by a working group at the Faculty level that included (beside the dean, associate dean, and quality assurance director) representatives of 15 working groups and resources. The representatives were associated with individual engineering programs, all science programs, common engineering courses, NSERC design chairs, FEAS teaching chairs, library, computer centre, health/safety office, and students.

The assessment process included the following tasks: (1) developing the learning objectives (LO) for the 12 graduate attributes, (2) mapping the graduate attributes and LO to all curriculum courses, (3) developing assessment schedule, (4) selecting courses from all four years for assessing five graduate attributes, (5) identifying assessment methods (direct and indirect), (6) developing assessment measures (e.g. rubrics, questions in exams, and surveys), (7) collecting and analyzing data, (8) identifying strength and weaknesses of the program, and (9) recommending improvements to the program (undertaken by curriculum committee and advisory council). Other important features of the process included the development of standard course outlines and cover pages for lab reports and assignments.

The LO for each of the 12 graduate attributes were developed for the faculty as a whole. Each of the eight engineering programs was assigned one or two specific graduate attributes and was asked to develop the respective $\mathrm{LO}$, keeping in mind that the $\mathrm{LO}$ would be applicable to all engineering programs. Each graduate attribute had a number of components (e.g. for communication skills, the components include writing skills and oral presentation skills). The developed LO were then circulated to all engineering programs and a final document was then prepared after a joint discussion by the working groups.

Each program has established a matrix that maps the graduate attributes and their components to curriculum courses. Table 1 shows the mapping of a specific course (CEN800: Law and Ethics in Engineering Practice).

Table 1: Mapping graduate attributes and courses (Example: CEN800)

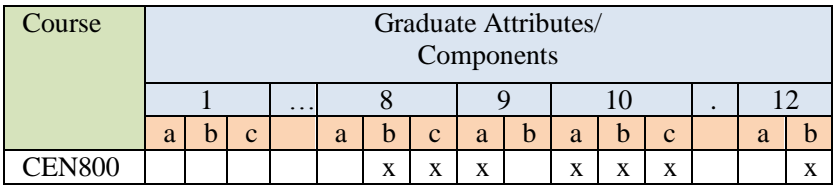

The five graduate attributes assessed during 2010/2011 were:

- Design

- Communication skills

- Professionalism

- Impact of engineering on society and environment

- Ethics and equity

During the next two years, 3 and 4 graduate attributes will be assessed, respectively. Thus all 12 graduate attributes will be evaluated in a three-year cycle, allowing each attributed to be evaluated twice during the six-year accreditation cycle.

The courses used for assessment included 3-5 program courses, 2 common engineering courses (CEN100: Introduction to Engineering and CEN800), and 3 first-year science courses (mathematics, physics, and computer science).
The direct assessment methods (developed by individual engineering programs) were:

- Rubrics for capstone reports

- Rubrics for oral presentations

- Exam/and assignment questions

The indirect assessment methods (developed by FEAS engineering chairs and used by all engineering programs) were:

- Student opinion surveys (exit survey and teamwork survey)

- Faculty opinion survey

RESULTS

Although this paper focuses on the assessment framework, some results were obtained for the fall 2010 semester and are presented here. The results correspond to the civil engineering program. Figure 1 shows the results of assessing communication skills using capstone projects. This attribute has five components: writing style (C1)), focus and flow of project (C2), grammar (C3), fluency in using current software (C4), and use of graphics (C5). The assessment rubric included three scales (poor, average, and excellent). The percentage of students with average/excellent performance is shown. A target of $90 \%$ was used. It is clear that improvements related to component $\mathrm{C} 4$ are needed.

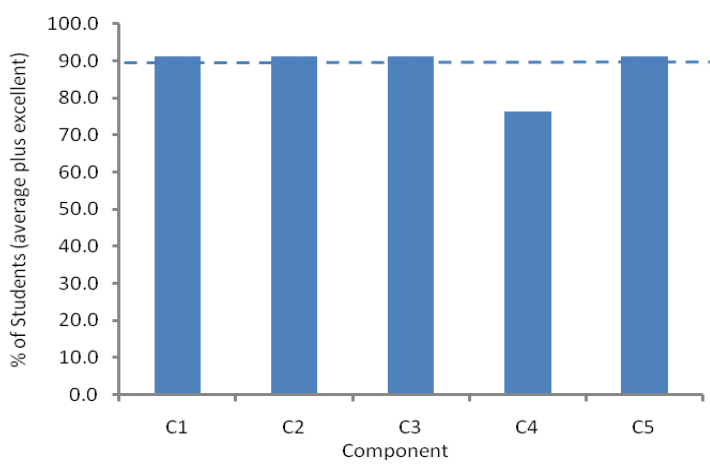

Figure 1: Student performance in components C1-C5 of the communication skills attribute

\section{DISCUSSION}

The key ingredients that have contributed to the success of the assessment process are: (a) continuous interaction between the quality assurance director and individual working groups (with nearly 50 meetings held), (b) frequent general meetings for engineering chairs and course instructors who conduct the assessment, (c) appointing a coordinator for the science courses which are taught to engineering students, and (d) several retreats at both the individual engineering program and Faculty levels.

Based on the experience gained during the development of this assessment system, the following learned lessons are highlighted:

(a) Appoint a Quality Assurance Leader. The leader would drive the process in a timely manner and provide consistency by acting as a focal point for guidance, inquiries, and clarification. The leader should attend relevant national and international workshops.

(b) Keep it Simple. Simplicity was achieved by assessing only five graduate attributes in the first year, selecting a few program courses for assessment, and developing the $\mathrm{LO}$ of the graduate attributes at the faculty level.

(c) Use Available University Resources. These included the Learning and Teaching office, the library, the computer and communications centre, NSERC design chairs, and FEAS teaching chairs.

\section{REFERENCE}

1. Spurlin J E, Rajala S A, and Lavelle J P (eds.) Designing better engineering education through assessment. Stylus Publishing, Sterling, Virgina, 2008 .

\section{AFFILIATED INSTITUTIONS FOR CO-AUTHORS}

* Director of Quality Assurance, FEAS.

** Dean, FEAS. 